\title{
Comparison of the post-mortem interval on the effect of vascular responses to the activation of ionotropic and metabotropic receptors
}

\author{
ELŻBIETA BLOCH-BOGUSŁAWSKA ${ }^{1}$, ELŻBIETA GRZEŚK ${ }^{2}$ and GRZEGORZ GRZEŚK ${ }^{2}$ \\ Departments of ${ }^{1}$ Forensic Medicine and ${ }^{2}$ Pharmacology and Therapeutics, \\ Collegium Medicum Nicolaus Copernicus University, Bydgoszcz 85-094, Poland
}

Received October 24, 2014; Accepted November 14, 2014

DOI: $10.3892 /$ br.2014.396

\begin{abstract}
The contractibility of blood vessels depends on their normal structure and the availability of calcium ions; it changes under the influence of numerous contracting and relaxing factors, which control the activities of various pathways of intracellular and intercellular signaling. The main aim of the study was to investigate, by means of perfusion pressure in rat tail arteries, the role of $\mathrm{Ca}^{2+}$ in vascular response to $\alpha-1$ adrenoceptor activation by phenylephrine (PHE) and Bay K8644 agonist of the L-type calcium channel and caffeine before and after a post-mortem interval (PMI) of 2, 4, 6 and $8 \mathrm{~h}$. A phasic increase of perfusion pressure in rat tail arteries, as induced by PHE or caffeine, in $\mathrm{Ca}^{2+}$-free solutions was used as an indicator of intracellular $\mathrm{Ca}^{2+}$ release through the inositol 1,4,5-triphosphate and ryanodine receptor pathways, respectively. In $\mathrm{Ca}^{2+}$-free-ethylene glycol tetraacetic acid (EGTA)-poly(sodium styrenesulfonate) (PSS) and in $\mathrm{Ca}^{2+}$-EGTA-PSS, the PHE induced elevation of perfusion pressure significantly decreased. Vascular responses to caffeine $(20 \mathrm{mmol} / \mathrm{l})$ in $\mathrm{Ca}^{2+}$-free-EGTA-PSS, with an increase of PMI from 2-8 h, did not change significantly. A similar effect was observed with vascular responses to $\mathrm{KCl} 40 \mathrm{mmol} / 1$ in $\mathrm{Ca}^{2+}$-EGTA-PSS. To confirm whether the inhibitory effect of 2, 4, 6 and $8 \mathrm{~h}$ PMI was mediated through the formation of NO, nitro-L-arginine (L-NNA), a potent NO synthase inhibitor, was used. Exposure to L-NNA $\left(10^{-5} \mathrm{M}\right)$ blocked the inhibition induced by an increase of PMI. The blocked effects of L-NNA
\end{abstract}

Correspondence to: Dr Elżbieta Bloch-Bogusławska, Department of Forensic Medicine, Collegium Medicum Nicolaus Copernicus University, 9 M. Sklodowskiej-Curie Street, Bydgoszcz 85-094, Poland

E-mail: ellabloch@gmail.com

Dr Elżbieta Grześk, Department of Pharmacology and Therapeutics, Collegium Medicum Nicolaus Copernicus University, 9 M. Sklodowskiej-Curie Street, Bydgoszcz 85-094, Poland

E-mail: ellag@cm.umk.pl

Key words: post-mortem interval, vascular responses, nitric oxide synthase inhibitor, ionotropic and metabotropic receptors were reversed by L-arginine $\left(10^{-4} \mathrm{M}\right)$. In conclusion, these patterns of change in artery responses provide insight into the post-mortem change in the receptor-mediated signaling components in epithelial and smooth muscle cells, and support the further study of post-mortem vascular responses triggered by $\mathrm{G}$ protein-coupled receptors (metabotropic) and channel-linked receptors (ionotropic) as potential markers for estimating short and long-term PMIs, respectively.

\section{Introduction}

Blood vessel contractibility depends on their normal structure and the availability of calcium ions. The contractibility changes under the influence of numerous contracting (such as angiotensin II and endothelin-1) and relaxing [including nitric oxide (NO) and prostacyclin] factors, which control the activities of various pathways of intracellular and intercellular signaling. Perfusion pressure in rat tail arteries were investigated in the present study, to investigate the role of $\mathrm{Ca}^{2+}$ in vascular response to activation $\alpha-1$ adrenoceptor by phenylephrine (PHE) and Bay K8644 agonist of the L-type calcium channel and caffeine before and after a post-mortem interval (PMI) of 2, 4, 6 and $8 \mathrm{~h}$. An elevated intracellular concentration of free calcium ions is considered a primary toxic mechanism in tissue damage (1-5). Mobilization tissues and an influx of calcium has long been considered as a major mechanism of ischemic cell death induced by different means, including ischemia (7-10). The increased concentration of cytoplasmic free- $\mathrm{Ca}^{2+}$ following hypoxia is derived from an influx and release from intracellular storage, such as endoplasmic reticulum (ER) and mitochondria.

Previous evidence indicated that mobilization of the intracellular calcium is in itself sufficient to activate apoptosis (10). This is supported by our finding that inhibition of nitric oxide synthase (NOS) elevated resistance to treatment with $\mathrm{CaCl}_{2}$, which mimics hypoxic stress and leads to the influx of calcium $(5,6)$. Treatment with $300 \mu \mathrm{M} \mathrm{CaCl}_{2}$ is commonly used to mimic hypoxic insults in vivo and in vitro.

The decrease in calcium influx $\left(\mathrm{Ca}^{2+}\right)_{\mathrm{i}}$ can be observed through different mechanisms, including inhibition of $\mathrm{Ca}^{2+}$ entry across the plasma membrane and inhibition of intracellular $\mathrm{Ca}^{2+}$ release. $\mathrm{NO}$ has an inhibitory effect on $\mathrm{Ca}^{2+}$ entry through the voltage-gated calcium channel in vascular smooth 
muscle. Inconsistent results have been reported regarding how $\mathrm{NO}$ affects intracellular $\mathrm{Ca}^{2+}$ release. The vascular relaxation by $\mathrm{NO}$ is caused partly by the reduction of intracellular $\mathrm{Ca}^{2+}$ release. $\mathrm{NO}$ has been found to not influence $\arg ^{8}$-vasopressin-induced intracellular $\mathrm{Ca}^{2+}$ release (5).

The present study was designed to investigate whether NO interfered with the $\mathrm{Ca}^{2+}$ influx from the extracellular space and release from intracellular storage. L-NNA was used to analyze the role of NO in the modification of post mortem vascular reactivity. More over experiments on normal arteries and endothelium denudated arteries were performed to got clear results.

A phasic increase of perfusion pressure in rat tail arteries induced by $\mathrm{PHE}$ or caffeine in $\mathrm{Ca}^{2+}$-free solution was used as an indicator of intracellular $\mathrm{Ca}^{2+}$ release through the inositol 1,4,5-triphosphate $\left(\mathrm{IP}_{3}\right)$ and ryanodine receptor pathways, respectively. In $\mathrm{Ca}^{2+}$-free-ethylene glycol tetraacetic acid (EGTA)-poly(sodium styrenesulfonate) (PSS) in the presence Bay $\mathrm{K} 8644$ and $\mathrm{KCl}$ did not increase of perfusion pressure (11). Bay $\mathrm{K}$ and $\mathrm{KCl}$ induced an increase of perfusion pressure that was observed only in $\mathrm{Ca}^{2+}$-PSS. The increases of perfusion pressure induced by Bay $\mathrm{K}$ and $\mathrm{KCl}$ were used as an indicator of $\mathrm{Ca}^{2+}$-influx from extracellular space to cytoplasm through the $\mathrm{Ca}^{2+}$-channel in the cellular membrane.

The influence of PMI on the PHE and caffeine treatment evoked a phasic increase of perfusion pressure in $\mathrm{Ca}^{2+}$-free solution in endothelium intact and endothelium-denuded rat tail arteries were studied.

\section{Materials and methods}

Perfusion pressure study. A male Wistar rat (250-300 g) was anesthetized with sodium pentobarbital $(65 \mathrm{mg} / \mathrm{kg}$, intraperitoneally), and its tail artery was removed quickly and placed in cold Krebs' solution of the following composition ( $\mathrm{mmol} / \mathrm{l})$ : 115.0 NaCl, 5.0 KCl, 25.0 $\mathrm{NaHCO}_{3}, 1.2 \mathrm{NaH}_{2} \mathrm{PO}_{4}, 1.2 \mathrm{MgSO}_{4}$, $2.1 \mathrm{CaCl}_{2}$ and 11.0 glucose. Fat and connective tissues surrounding the rat tail arteries were removed carefully and the isolated artery was cannulated at the two ends. The tail arteries were then suspended in organ chambers containing $20 \mathrm{ml}$ of Krebs-Ringer bicarbonate solution containing ( $\mathrm{mmol} / \mathrm{l})$ 118.3 NaCl, 4.7 KCl, 1.2 $\mathrm{MgSO}_{4}, 1.2 \mathrm{KH}_{2} \mathrm{PO}_{4}, 2.5 \mathrm{CaCl}_{2}$, $25.0 \mathrm{NaHCO}_{3}$ and 11.1 glucose (control solution) at $37^{\circ} \mathrm{C}$ and bubbled through with $95 \% \mathrm{O}_{2}$ and $5 \% \mathrm{CO}_{2}$. One of the wires was anchored in the organ chamber and the other was connected to a pressure transducer Statham-Gould type P23ID connected with a polyphysiograph (Narco Bio System, Inc., Houston, TX, USA) Narcotrace 40 and digital recorder Graphtec midi Logger GL820 (Graphtec Corporation, Tokyo, Japan). The rat tail artery was equilibrated at an initial resting tension of $500 \mathrm{mg}$ and the buffer solution was changed every 15 min to stabilize the arterial tissues. The endothelium was removed from specific arteries when necessary. The removal of the endothelium was verified functionally by the lack of relaxant response to acetylcholine $\left(10^{-5} \mathrm{M}\right)$ in rat tail arteries precontracted with PHE $\left(10^{-6} \mathrm{M}\right)(12,13)$. The study protocol was approved by the Local Ethics Committee and all experiments were carried out in accordance with the United States NIH guidelines [Guide for the Care and Use of Laboratory Animals (1985), DHEW Publication No. (NIH) 85-23: Office of Science and Health
Reports, DRR/NIH, Bethesda, MD, USA]. The study used 15 animals. All animals were purchased from Trójmiejska Akademicka Zwierzętarnia Doświadczalna Centrum Badawczo Usługowe GUMed (Gdańsk, Poland).

$\mathrm{Ca}^{2+}$-free-EGTA solution was prepared by the omission of $\mathrm{CaCl}_{2}$ and the addition of $0.2 \mathrm{mmol} / \mathrm{l}$ EGTA. Prior to data collection, all the rat tails were contracted with PHE $\left(10^{-6} \mathrm{M}\right)$ or caffeine $(20 \mathrm{mmol} / \mathrm{l})$ in $\mathrm{Ca}^{2+}$-free solution for $5 \mathrm{~min}$ to deplete the internal $\mathrm{Ca}^{2+}$ sources.

As the second application of the agonists was significantly diminished, the arterial tissues were subsequently washed with $\mathrm{Ca}^{2+}$-containing Krebs solution three times and incubated for $15 \mathrm{~min}\left(\mathrm{Ca}^{2+}\right.$ loading time). Following this the medium was replaced by $\mathrm{Ca}^{2+}$-free solution and 5 min later PHE $\left(10^{-6} \mathrm{M}\right)$ or caffeine $(20 \mathrm{mmol} / \mathrm{l})$ was applied to produce a phasic increase of perfusion pressure. Only those tissues exhibiting repeated perfusion pressure responses of a similar magnitude in $\mathrm{Ca}^{2+}$-free solution were selected. In all the experiments, L-NNA, L-arginine, D-arginine, sodium nitroprusside (SNP; 10-7M) and $1 \mathrm{H}-[1,2,4]$ oxadiazolo[4,3- $\alpha]$ quinoxalin-1-one (ODQ; 10-5M) were added to the organ chambers at the beginning of the incubation period with $\mathrm{Ca} 2+$-free solution. SNP and ODQ were purchased from Sigma Aldrich (Poznan, Poland).

Data analysis. The results are presented as means \pm standard error. Statistical analysis was performed using the Newman-Keuls test for multiple comparison of the means, and $\mathrm{P}<0.05$ was considered to indicate a statistically significant difference.

\section{Results}

PMI on perfusion pressure. The influence of PMI on perfusion pressure induced by PHE, caffeine, Bay K8644 and $\mathrm{KCl}$ was investigated in rat tail arteries in $\mathrm{Ca}^{2+}$-EGTA-PSS, $\mathrm{Ca}^{2+}$-free-EGTA-PSS, with and without endothelium.

PHE $\left(10^{-6} \mathrm{M}\right)$ and caffeine $(20 \mathrm{mmol} / \mathrm{l})$ evoked a rapid increase of the perfusion pressure of the rat tail arteries in $\mathrm{Ca}^{2+}$-free solution, $137 \pm 12$ and $73 \pm 12 \mathrm{mmHg}$, respectively (Fig. 1). Perfusion pressure reached its maximal levels within $40 \mathrm{sec}$ and declined thereafter without a sustained perfusion pressure. To exclude the possibility that residual $\mathrm{Ca}^{2+}$ in $\mathrm{Ca}^{2+}$-free solution may play a role in the contractile responses, $\mathrm{KCl}$ (40 mmol/l), which can only stimulate $\mathrm{Ca}^{2+}$ entry through the plasma membrane, was applied after incubation with $\mathrm{Ca}^{2+}$-free solution for $5 \mathrm{~min}$, but it could not induce an increase of perfusion pressure. Bay K8644 $\left(10^{-6} \mathrm{M}\right)$, which can stimulate only $\mathrm{Ca}^{2+}$ entry through the plasma membrane, was also applied after incubation with $\mathrm{Ca}^{2+}$-free solution for $5 \mathrm{~min}$, but it also could not induce an increase perfusion pressure. Thus, an increase of perfusion pressure induced in $\mathrm{Ca}^{2+}$-free-EGTA-PSS by PHE and caffeine are caused by intracellular $\mathrm{Ca}^{2+}$-release by two different mechanisms, $\mathrm{IP}_{3}$-dependant and -independent, respectively.

In $\mathrm{Ca}^{2+}$-EGTA-PSS solution, PHE and caffeine induced a significantly greater increase of perfusion pressure, which reached $183 \pm 11 \mathrm{mmHg}(\mathrm{n}=16)$ and $93 \pm 16 \mathrm{mmHg}(\mathrm{n}=14)$ respectively. Furthermore, $\mathrm{KCl}$ and Bay K8644 induced an increase of perfusion pressure in $\mathrm{Ca}^{2+}$-EGTA-PSS only. A mean value of maximal perfusion pressure obtained with $\mathrm{KCl}$ 


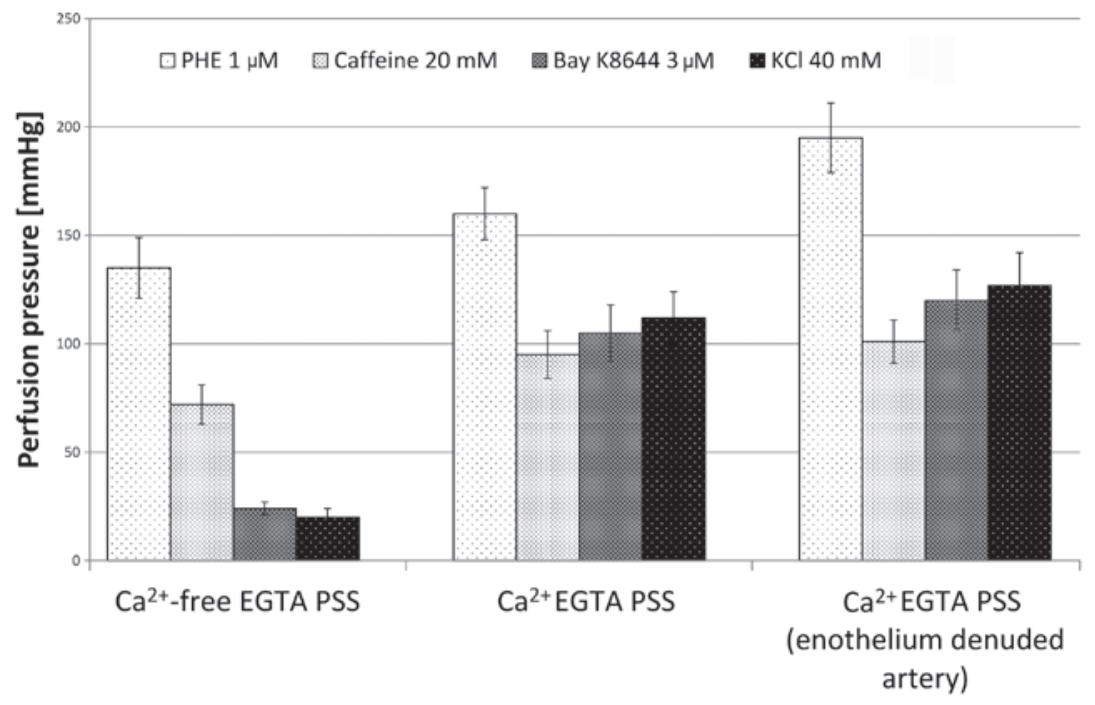

Figure 1. Response of perfused rat tail artery to $1 \mu \mathrm{M}$ phenylephrine (PHE), $20 \mathrm{mmol} / \mathrm{l}$ caffeine, $3 \mu \mathrm{M}$ Bay K8644 and $40 \mathrm{mmol} / 1 \mathrm{KCl}$ in the Ca ${ }^{2+}$-ethylene glycol tetraacetic acid (EGTA)-poly(sodium styrenesulfonate) (PSS) and $\mathrm{Ca}^{2+}$-free-EGTA-PSS for control and endothelium-denuded arteries. Data represent means \pm standard error of the mean for four experiments.

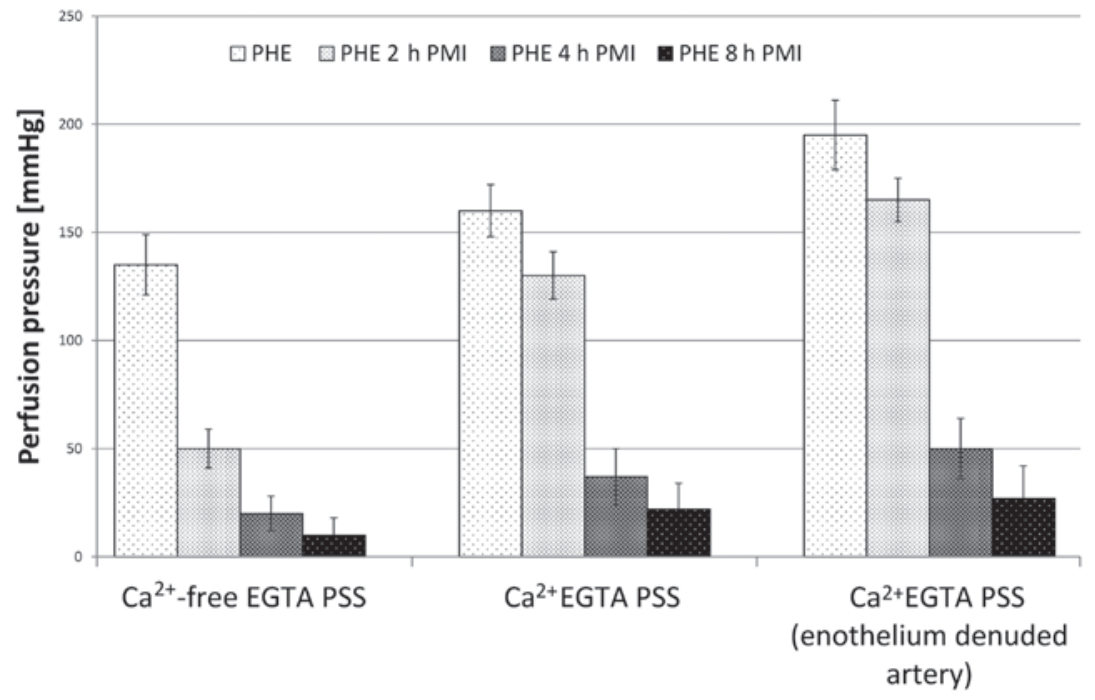

Figure 2. Influence of post-mortem interval (PMI) $(2,4$ and $8 \mathrm{~h})$ on the responses of perfused rat tail arteries to $1 \mu \mathrm{M}$ phenylephrine (PHE) in the Ca ${ }^{2+}$-EGTA-PSS and $\mathrm{Ca}^{2+}$-free-ethylene glycol tetraacetic acid (EGTA)-poly(sodium styrenesulfonate) (PSS) for control and endothelium-denuded arteries. Data represent means \pm standard error for $n=16$.

(40 mmol/l) and Bay K8644 reached 116 \pm 15 and $84 \pm 10 \mathrm{mmHg}$, respectively (Fig. 1).

In the $\mathrm{Ca}^{2+}$-free-EGTA-PSS solution after an increase of PMI from 2-8 h, PHE induced elevation of perfusion pressure significantly decreased. After $2 \mathrm{~h}$ PMI, an increase of maximal perfusion pressure induced by $\mathrm{PHE}$ reached $49 \pm 14 \mathrm{mmHg}$ only $(n=16)$. Furthermore, an increase of PMI to 4 and 8 h depleted the response on PHE to $16 \pm 9$ and $8 \pm 7 \mathrm{mmHg}$, respectively (Fig. 2). PHE also induced an increase of perfusion pressure in $\mathrm{Ca}^{2+}$-EGTA-PSS, which significantly decreased with the increase of PMI. The mean maximal response to PHE reached $183 \pm 22 \mathrm{mmHg}$ in the control and after 2, 4 and $8 \mathrm{~h}$ PMI depleted to $137 \pm 23,34 \pm 12$ and $18 \pm 9 \mathrm{mmHg}$, respectively (Fig. 2).

By contrast, rat tail artery responses to caffeine (20 mmol/l) in $\mathrm{Ca}^{2+}$-free-EGTA-PSS solution did not change significantly with an increase of PMI from 2-8 h (Fig. 3). The mean maximal responses oscillated from $78 \pm 15 \mathrm{mmHg}$ after $2 \mathrm{~h}$ PMI to $62 \pm 11 \mathrm{mmHg}$ after $8 \mathrm{~h}$ PMI (Fig. 3).

Similar effects in $\mathrm{Ca}^{2+}$-EGTA-PSS were observed with $\mathrm{KCl}(40 \mathrm{mmol} / \mathrm{l})$, which induced an increase in perfusion pressure of the rat tail arteries. In this condition, the mean maximal responses slightly decreased and oscillated between $116 \pm 15 \mathrm{mmHg}$ in the control response and $121 \pm 17$, $119 \pm 14$ and $98 \pm 12 \mathrm{mmHg}$ after 2, 4 and $8 \mathrm{~h} \mathrm{PMI}$, respectively (Fig. 4).

\section{Discussion}

The estimation of PMI remains an ambiguous problem in forensic investigations (3). The use of calmodulin (CaM) binding proteins (CaMBPs) as indicators of PMI has been investigated previously. In lung tissue samples, $\mathrm{Ca}^{2+} / \mathrm{CaM}$-dependent protein 


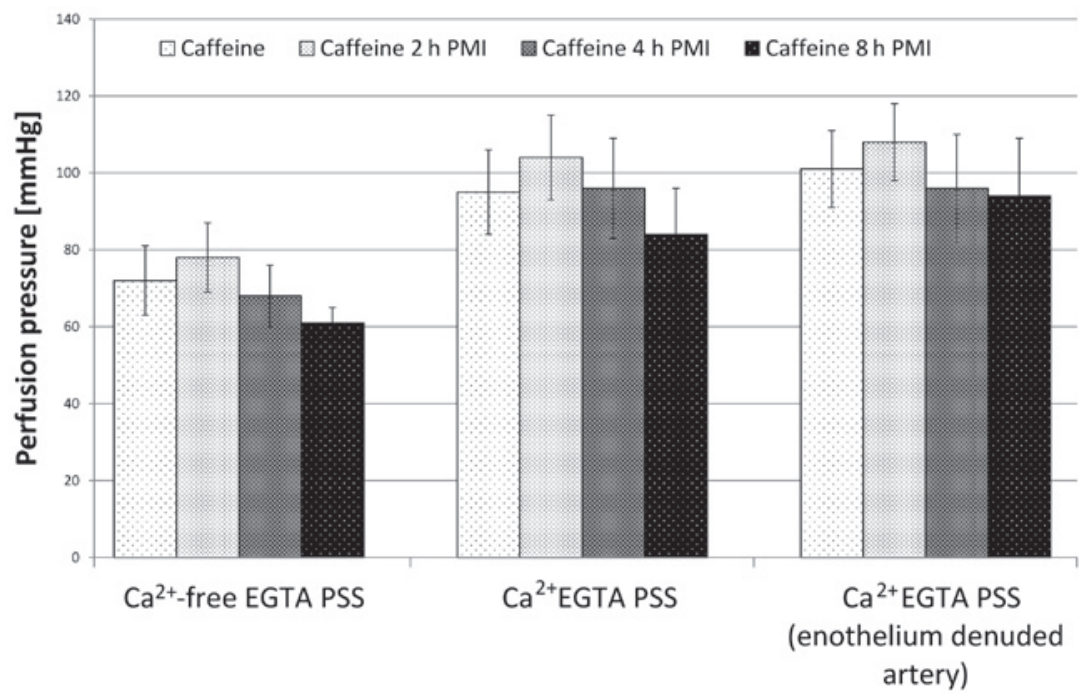

Figure 3. Influence of post-mortem interval (PMI) $\left(2,4\right.$ and $8 \mathrm{~h}$ ) on the responses of perfused rat tail arteries to $20 \mathrm{mmol} / \mathrm{l}$ caffeine in the $\mathrm{Ca}^{2+}$-ethylene glycol tetraacetic acid (EGTA)-poly(sodium styrenesulfonate) (PSS) and $\mathrm{Ca}^{2+}$-free-EGTA-PSS for control and endothelium-denuded arteries. Data represents means \pm standard error for $\mathrm{n}=12$.

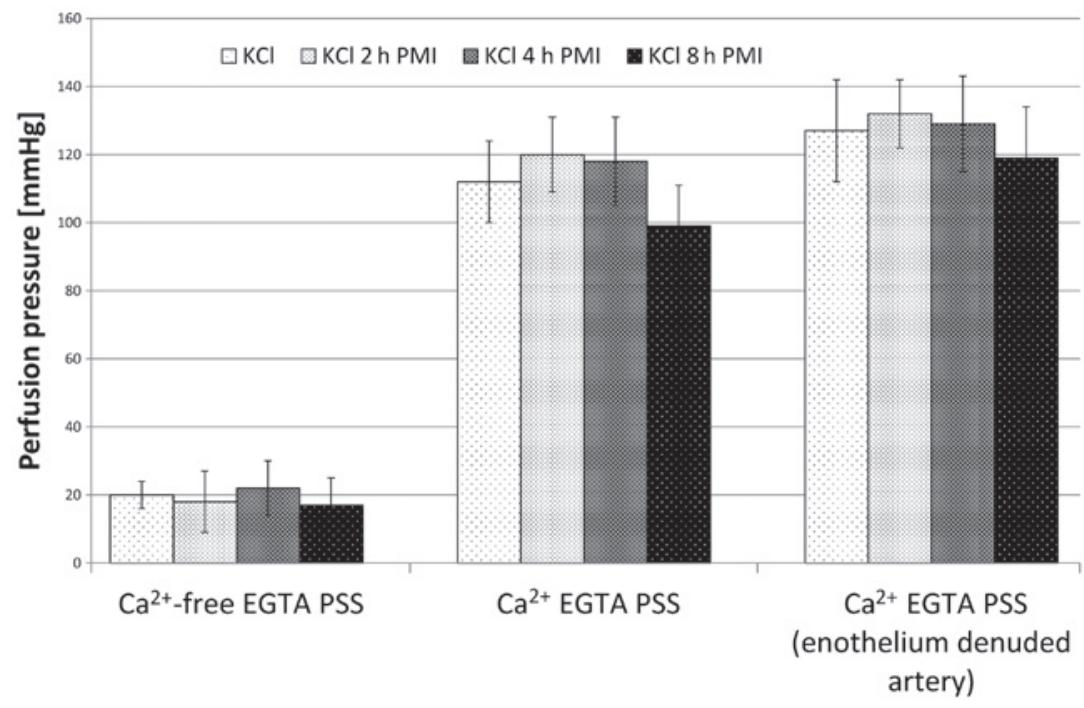

Figure 4. Influence of post-mortem interval (PMI) $\left(2,4\right.$ and $8 \mathrm{~h}$ ) on the responses of perfused rat tail arteries to $40 \mathrm{mmol}_{1} \mathrm{KCl} \mathrm{K}_{\text {, in }}$ the $\mathrm{Ca}^{2+}$-ethylene glycol tetraacetic acid (EGTA)-poly(sodium styrenesulfonate) (PSS) and $\mathrm{Ca}^{2+}$-free-EGTA-PSS for control and endothelium-denuded arteries. Data represents means \pm standard error for $\mathrm{n}=14$.

kinase II (CaMKII) levels did not significantly change over the $96 \mathrm{~h}$ PMI time period examined. The stability of CaMKII levels over $96 \mathrm{~h}$ was also observed in skeletal muscle tissue, whereas calcineurin A (CNA) showed variable levels at 0,48 and $96 \mathrm{~h}$ with the presence of the rapidly migrating band at $24 \mathrm{~h}$. Kang et al analyzed specific CaMBPs, $\mathrm{Ca}(2+) / \mathrm{CaM}$-dependent kinase II, calcineurin A in immunoblot analysis. These patterns of change in CaMBPs provide insight into the post-mortem changes in CaM-mediated signaling components in lung and skeletal muscle and support the further study of CNA and CaMKII as potential markers for estimating short- and long-term PMIs (3).

By contrast, inducible NOS levels, which vary between samples, CNA and myristoylated alanine-rich C-kinase substrate (MARCKS) exhibited predictable patterns of change; the level of MARCKS decreased steadily in the 0-96 h post-mortem lung samples (14).
In the present study, the possible use of vascular responses to PHE, Bay $\mathrm{K}$, caffeine and $\mathrm{KCl}$ were examined as indicators of PMI. All the models were allowed to determine the time of laying within a period of $\sim 2 \mathrm{~h}$ and consequently this was determined as the time of death; under favorable conditions the species lays immediately following death.

The majority of systemic vessels relax, but pulmonary vessels contract when exposed to hypoxia; the mechanisms are likely to be diverse. Vascular and cardiac endothelium releases are the last three chemical messengers that may influence vascular and cardiac performance. First, endothelial cells express NOS (constitutive and inducible form). NO release by endothelial cells has been shown to elevate vascular cGMP. Post-mortem, the energy metabolism is disrupted and the endothelial cells lose $\mathrm{Ca}^{2+}$ from the ER and the cytosolic $\mathrm{Ca}^{2+}$ concentration increases. An increase in $\mathrm{Ca}^{2+}$ may also occur under pathophysiological 
conditions, such as during hypoxia or ischemia, when the endothelial cells start developing an energy deficit. The study by Coburn et al (15) indicated that hypoxic relaxation is not only a function of energy stores, and that oxidative metabolism-contraction coupling is regulated by energy delivery to a reaction, or reactions that are controlling muscle force.

Tosun et al (9) suggested that oxygen sensing mechanisms may modulate the cell signaling pathways involved in excitation-contraction coupling, including mechanisms in which $\mathrm{Ca}^{2+}$ is the regulated parameter, for example by oxygen-dependent or adenosine triphosphate-dependent changes in $\mathrm{Ca}^{2+}$ permeability.

The present study investigated, by means of perfusion pressure in rat tail arteries, the role of the $\mathrm{Ca}^{2+}$ in vascular response to activation of $\alpha-1$ adrenoceptor by PHE and Bay K8644 (agonist of L-type calcium channel) before and after 2, 4, 6 and $8 \mathrm{~h}$ PMI. A phasic increase of perfusion pressure in the rat tail arteries induced by PHE or caffeine in $\mathrm{Ca}^{2+}$-free solution were used as an indicator of intracellular $\mathrm{Ca}^{2+}$ release through the inositol $\mathrm{IP}_{3}$ and ryanodine receptor pathways, respectively. Bay $\mathrm{K} 8644$ and $\mathrm{KCl}$ induced an increase in perfusion pressure in $\mathrm{Ca}^{2+}$-PSS only, and this increase was used as an indicator of $\mathrm{Ca}^{2+}$-influx from the extracellular space to the cytoplasm through the $\mathrm{Ca}^{2+}$-channel in the cellular membrane. The influence of PMI on the PHE- and caffeine-induced phasic contractions in $\mathrm{Ca}^{2+}$-free solution in the intact endothelium and endothelium denuded rat tail arteries was studied.

To confirm whether the inhibitory effect of 2, 4, 6 and $8 \mathrm{~h}$ PMI was mediated through NO formation, L-NNA was used and compared to the effect of the inhibitor, COX indomethacin. Exposure to L-NNA $\left(10^{-5} \mathrm{M}\right)$ blocked the inhibition induced by increase PMI. The blocked effects of L-NNA could be reversed by L-arginine $\left(10^{-4} \mathrm{M}\right)$. An elevated intracellular concentration of free calcium ions is considered a primary toxic mechanism in tissue damage (2,16-18). Mobilization tissues and the influx of calcium has long been considered as a major mechanism of ischemic cell death induced by different means, including ischemia (7,19-21). The increased concentration of cytoplasmic free $\mathrm{Ca}^{2+}$ following hypoxia is derived from an influx and release from intracellular storage, such as ER and mitochondria $(6,8,22)$.

Previous evidence indicated that mobilization of the intracellular calcium is in itself sufficient to activate apoptosis (14). This is supported by the finding that NOS inhibition elevated the resistance to treatment with $\mathrm{CaCl}_{2}$, which mimics hypoxic stress and leads to the influx of calcium $(4,6,22)$. Treatment with $300 \mu \mathrm{M} \mathrm{CaCl}_{2}$ is commonly used to mimic hypoxic insults in vivo and in vitro.

In conclusion, these patterns of change in arteries responses provide insight into the post-mortem change in receptor mediated signaling components in epithelial and smooth muscle cells and support the further study of post-mortem vascular responses triggered by $\mathrm{G}$ protein coupled receptors (metabotropic) and channel linked receptors (ionotropic) as potential markers for estimating short- and long-term PMIs, respectively.

\section{References}

1. Blatter LA and Wier WG: Nitric oxide decreases $\left[\mathrm{Ca}^{2+}\right]_{\mathrm{i}}$ in vascular smooth muscle by inhibition of the calcium current. Cell Calcium 15: 122-131, 1994.
2. Colton CA, Fagni L and Gilbert D: The action of hydrogen peroxide on paired pulse and long term potentiation in the hippocampus. Free Radic Biol Med 7: 3-8, 1989.

3. Kang S, Kassam N, Gauthier ML and O'Day DH: Post-mortem changes in calmodulin binding proteins in muscle and lung. Forensic Sci Int 131: 140-147, 2003.

4. Koh JY and Choi DW: Quantitative determination of glutamate mediated cortical neuronal injury in cell culture by lactate dehydrogenase efflux assay. J Neurosci Methods 20: 83-90, 1987.

5. Grześk G, Wiciński M, Malinowski B, Grześk E, Manysiak S, Odrowąż-Sypniewska G, Darvish N and Birwagen M: Calcium blockers inhibit cyclosporine A-induced hyperreactivity of vascular smooth muscle cells. Mol Med Rep 5: 1469-1474, 2012.

6. Slupski M, Szadujkis-Szadurski L, Grześk G, Szadujkis-Szadurski R, Szadujkis-Szadurska K, Wlodarczyk Z, Masztalerz M, Piotrowiak I and Jasiński M: Guanylate cyclase activators influence reactivity of human mesenteric superior arteries retrieved and preserved in the same conditions as transplanted kidneys. Transplant Proc 39: 1350-1353, 2007.

7. Depre C, Fierain L and Hue L: Activation of nitric oxide synthase by ischemia in the perfused heart. Cardiovasc Res 33: 82-87, 1997.

8. Ikonomidou C, Mosinger JL, Salles KS, Labruyere J and Olney JW: Sensitivity of the developing rat brain to hypobaric/ischemic damage parallels sensitivity to $\mathrm{N}$-methyl-aspartate neurotoxicity. J Neurosci 9: 2809-2818, 1989.

9. Tosun M, Paul RJ and Rapoport RM: Intracellular $\mathrm{Ca}^{2+}$ elevation and contraction due to prostaglandin $\mathrm{F}_{2 \alpha}$ in rat aorta. Eur J Pharmacol 340: 203-208, 1997.

10. Willmott NJ, Galione A and Smith PA: Nitric oxide induces intracellular $\mathrm{Ca}^{2+}$ mobilization and increases secretion of incorporated 5-hydroxytryptamine in rat pancreatic $\beta$-cells. FEBS Lett 371: 99-104, 1995.

11. Bloch-Bogusławska E: The effect of the time of death on the reactivity of rat caudal artery regulated by Bay-K 8644 (an agonist directly affecting the Ca channel). Arch Med Sadowej Kryminol 56: 132-135, 2006 (In Polish).

12. Grześk G and Szadujkis-Szadurski L: Pharmacometric analysis of $\alpha 1$-adrenoceptor function in rat tail artery pretreated with lipopolysaccharides. Pol J Pharmacol 53: 605-613, 2001.

13. Grześk G, Kozinski M, Tantry US, Wicinski M, Fabiszak T, Navarese EP, Grzesk E, Jeong YH, Gurbel PA and Kubica J: High-dose, but not low-dose, aspirin impairs anticontractile effect of ticagrelor following ADP stimulation in rat tail artery smooth muscle cells. Biomed Res Int 2013: 928271, 2013.

14. Kanner J, Harel S and Granit R: Nitric oxide, an inhibitor of lipid oxidation by lipooxygenase, cyclooxygenase and hemoglobin. Lipids 27: 46-49, 1992.

15. Coburn RF, Moreland S, Moreland RS and Baron CB: Rate-limiting energy-dependent steps controlling oxidative metabolism-contraction coupling in rabbit aorta. J Physiol 448: 473-492, 1992.

16. Aizenman E, Hartnett KA and Reynolds IJ: Oxygen free radicals regulate NMDA receptor function via a redox modulatory site. Neuron 5: 841-846, 1990.

17. Bredt DS, Hwang PM and Snyder SH: Localization of nitric oxide synthase indicating a neural role for nitric oxide. Nature 347: 768-770, 1990.

18. Choi DW: Nitric oxide: foe or friend to the injured brain? Proc Natl Acad Sci USA 90: 9741-9743, 1993.

19. Brenman JE, Chao DS, Gee SH, McGee AW, Craven SE, Santillano DR, Wu Z, Huang F, Xia H, Peters MF, et al: Interaction of nitric oxide synthase with the postsynaptic density protein PSD-95 and $\alpha 1$-synthropin mediated by PDZ domains Cell 84: 757-767, 1996.

20. Choi DW: Glutamate neurotoxicity and diseases of the nervous system. Neuron 1: 623-634, 1988.

21. Furchgott RF and Vanhoutte PM: Endothelium-derived relaxing and contracting factors. FASEB J 3: 2007-2018, 1989.

22. Szadujkis-Szadurska K, Grzesk G, Szadujkis-Szadurski L, Gajdus M and Matusiak G: Role of nitric oxide and cGMP in the modulation of vascular contraction induced by angiotensin II and Bay K8644 during ischemia/reperfusion. Exp Ther Med 5: 616-620, 2013. 